\title{
NEPALI MIGRANT LABOURERS ARE HIGHLY EXPOSUED TO UNSAFE SEXUAL BEHAVIOUR
}

Ghimire Madhusudan ${ }^{1}$, Singh Anand Pratap ${ }^{2}$, Ghimire Moushami ${ }^{3}$

\begin{abstract}
INTRODUCTION: Unsafe sexual behavior between two partners may lead to incidence of STDs/HIV/ AIDS and can create serious problems in society. Both biological and behavioural variables are playing significant role to determine sexual activities of humans and result may end the probability that infection will occur after unsafe sexual contact between a susceptible and infected partner.
\end{abstract}

OBJECTIVES: To study high risk sexual behaviour among the Nepali migrant labourers in India.

METHODS: A cross-sectional survey of 240 Nepali migrant labourers temporarily residing in India was carried out. A brief interview schedule was used to collect information.

RESULTS: Most of the Nepali migrant workers (below 30 years) were involved in high risk sexual behaviour. 74.58 percent were exposure to unsafe physical relation.

CONCLUSION: Migrants labourers below 30 years with no formal education were involved in high risk behaviour and they could be exposed to STDs/HIV/AIDS.

KEYWORDS: Age, India, Nepali migrant labourers, Pornographic events, sexual behaviour

1. Dr. Madhusudan Ghimire, Asst.prof. Community Medicine Department, LMC Palpa.

2. Dr. A.P. Singh, Asso. Prof. Community Medicine Department, LMC Palpa.

3. Mrs. Moushami Ghimire, Lecturer, Community Medicine Department, LMC Palpa.

\author{
For Correspondance: \\ Dr. Madhusudan Ghimire \\ Assistant Professor \\ Community Medicine Department \\ LMC Palpa \\ E-mail:1mcpalpa@gmail.com
}




\section{INTRODUCTION}

Sex has many dimensions. It is the means of procreation; but can also be used to express the emotional side of love and friendship, just as a material gift would do. Sex and material gifts can therefore be exchanged in a non-commercial transaction when they have the same emotional values. The exchange can occur in both marital and non-marital sexual negotiations because it is inherent in them. This raises a serious question when considering the dividing lines between commercial and affectional sex. In the former, sex is commoditized, sold and bought: there is a fixed or negotiated price attached to the sexual act. In the latter, sex is meant to express the emotional sides of love and friendship; it is determined by religious, cultural and procreational morality. Affectionl sex is thus linked to both the individual character and the societal moral attributes. This two categories are not mutually exclusive, and they both involve the circulation of material objects in their negotiations. In the context of Nepal, most of illiterate people with low socioeconomic status are working as labourer in different parts of India. Most of the migrant labourer are unaware about healthy sexual behavior and may involve in unsafe sexual activities. These all activities of migrants may lead to them for getting STD/HIV/AIDS. 200,000 Nepali sex workers are in India. ${ }^{1}$ Nepal's HIV epidemic figure also shows that number of sex workers who migrate or are trafficked to Mumbai, India to work, thereby increasing HIV prevalence in the sex workers' network in Nepal. ${ }^{2}$

\section{Material and Method}

Cross sectional analytical study design was applied among the 240 Nepali migrant labourers who were working temporally in different parts (Allahabad, Vanarasi, Hariyana and Delhi) of India. Respondents were selected through simple random process. Information was collected through pre tested interview schedule, key informant and focus group discussion. The detail information about study was provided to the respondents and tried to fulfill their enquiries. Anonymity of all participants was maintained and, saved their wishes and expression. Information was analyzed through SPSS Microsoft process.

\section{RESULTS}

1. Demographic profile of respondents

\begin{tabular}{|c|l|c|c|}
\hline \multirow{4}{*}{ Education } & & Frequency & Percent \\
\cline { 2 - 4 } & Illiterate & 63 & 26.2 \\
\cline { 2 - 4 } & Primary & 93 & 38.8 \\
\cline { 2 - 4 } & Lower secondary & 64 & 26.7 \\
\cline { 2 - 4 } & S.L.C. & 20 & 8.3 \\
\hline \multirow{2}{*}{ Age } & Below 20 years & 10 & 4.2 \\
\cline { 2 - 4 } & 20 to 30 years & 164 & 68.3 \\
\cline { 2 - 4 } & 31 to 40 years & 51 & 21.2 \\
\cline { 2 - 4 } & Above 40 years & 15 & 6.2 \\
\hline \multirow{2}{*}{ Marital Status } & Married & 108 & 55.0 \\
\cline { 2 - 4 } & Non-married & & 45.0 \\
\hline
\end{tabular}

2. Exposure to physical relation with condom use

\begin{tabular}{|l|c|c|c|}
\hline Exposure to physical relation & & No. of labourer & Percent \\
\cline { 2 - 4 } & Yes & 179 & 74.58 \\
\cline { 2 - 4 } & No & 61 & 25.42 \\
\hline Condom used during last physical relation (N=179) & Yes & 99 & 55.03 \\
\cline { 2 - 4 } & No & 80 & 44.97 \\
\hline
\end{tabular}


3. Cross tabulation between Age and education level of the migrant laborer and Exposure to pornographic movies

\begin{tabular}{|c|c|c|c|}
\hline \multirow[t]{2}{*}{ 1. Age of the responds } & \multicolumn{2}{|c|}{ Exposure to pornographic movies } & \multirow[t]{2}{*}{ Total } \\
\hline & yes & No & \\
\hline Below 20 years & 7 & 3 & 10 \\
\hline 20 to 30 years & 148 & 16 & 164 \\
\hline 31 to 40 years & 44 & 7 & 51 \\
\hline Above 40 years & 13 & 2 & 15 \\
\hline \multicolumn{4}{|l|}{ Pearson Chi-Square $0.252, \mathrm{df}=3$} \\
\hline \multicolumn{4}{|c|}{ 2. Education of the respondents } \\
\hline illiterate & 58 & 5 & 63 \\
\hline primary & 81 & 12 & 93 \\
\hline lower secondary & 55 & 9 & 64 \\
\hline S.L.C. & 18 & 2 & 20 \\
\hline Pearson Chi-Square $0.706, \mathrm{df}=3$ & & & \\
\hline
\end{tabular}

\section{DISCUSSION}

Sexual behavior is related to sex and sex perception of people. It is influenced by culture, social structure, age, sex, education, sexual knowledge, attitude and nature of every individual. Some sexual behaviors are classified as high risk behavior and lead to increase risk of sexually transmitted diseases. Education can play major role for inducing healthy practices which may help to promote safe sexual behavior. Adolescents' education level even within the same socio-economic class is a key determinant of their own reproductive health. Social, economical and political disruptions often involve simultaneous sudden increase in the number of migration and prostitutes. ${ }^{7}$ The study found that $26.2 \%$ of total respondents were illiterate and $38.8 \%$ migrant labourers were able to read and write but they could not have sufficient knowledge regarding sexual behaviour. $45 \%$ unmarried migrants were fall in high risk sexual behavior. A joint study conducted by Harvard school of public health in kalilali district of Nepal stated that sexually transmitted infection among the women in migrant communities was high. Age, mariatal status and migration status of their husbands were more associated to high risk sexual activities and sexually transmitted infections ${ }^{1}$. The study revealed that maximum of total study population were exposure to pornographic movies so it could lead to involve into unsafe physical relation. A similar study conducted in Malawi stated that 95.5 percent of 163 migrant were involved in friendship non- commercial sexual contact and they had multi-partnered sexual behaviour ${ }^{4} .51 .5$ percent of them had more than five regular sexual partners and involved in unsafe $\operatorname{sex}^{3}$. The study agreed that age of the respondents was associated (Pearson Chi-Square 0.252, $\mathrm{df}=3$ ) with exposure to pornographic movies but not observable relation between educational status of migrants labourer with pornographic movies. On the observation of behavioural factors of the respondents the study stated that most of them were at high risk of getting unsafe sex and 44.97 percent of total exposure migrants could not use condom to their last physical relation but 82 percent of total migrated truck drivers in Thailand were involved unsafe commercial sexual relation ${ }^{5}$.

\section{CONCLUSION}

Migrants below 30 years with no education as well as low education were exposed to high risk sexual behavior. Age of the migrant was significantly observable on exposure to pornographic movies. 


\section{REFERENCES}

1. Allison,S.E.etal. "Sexually transmitted infection among the women in migrant communities in kailali district". A joint study of Harvard school of public health, Save the children U.S. The Nepal initiative.kathmandu,Nepal. 2001

2. ANNUAL REPORT. "HIV/AIDS Situation in Nepal”. Department of Health Services, Nepal. 2006.

3. Chirwa, W.C. "The Malawi government and South African labour recruiters, 1974-92”. Journal of Modern African Studies.1996 34 (4):623-642.

Chirwa, W.C. "Migrant Labours, Sexual Networking and multinered sex in Malawi”. Health transition Review, supplement 3 to volume7,1997:5 15
5. Giraud, Patrick. "The economic impact of AIDS at a sectoral leveling Bloom”. Economic implication of AIDS in Asia. HIVIAIDS regional project, UNDP.1993.

6. Park, J.E; Park, K. "Text book of preventive and social medicine" M/s Banarsidas Bhanot, 1167, India. 1991

7. UNAIDS. "Working with mean for HIV prevention and care" Geneva, Switzerland. 2001: 22.

8. Waver, et al. "Origin and work condition of female sex workers in urban Thailand: consequence of social context for HIV transmission". Journal of Social science and Medicine, 1996 42(3). 453- 462 .

\section{Universal College of Medical Sciences and Teaching Hospital Our Academic Programmes}

$>$ MBBS

$>\mathrm{BDS}$

$>$ MD/MS (Surgery, Paediatrics, Orthopaedics, Radiology, Anesthesia, Psychiatry, Medicine, Gynecology, ENT, Dermatology, Ophthalmology, Pathology, Microbiology, Anatomy, Pharmacology, MDGP)

$>$ MDS (Oral \& Maxillofacial Surgery, Periodontics, Conserative Dentistry \& Endodontics, Orthodontics \& Dentofacial Orthopedics, Prosthodontics \& Maxillofacial Prosthetics)

$>$ Bsc. Nursing

$>$ Bachelor in Nursing (B.N.)

$>$ Bachelor in Pharmacy (B.Pharma)

$>$ Bachelor in Medical Laboratory Technology (BMLT) 